\title{
Ragam Pengukuran Kinerja pada Usaha Mikro, Kecil, dan Menengah (UMKM) di Surabaya
}

\author{
Islami A.C., Kunaifi A., dan Gunawan J. \\ Departemen Manajemen Bisnis, Fakultas Bisnis dan Manajemen Teknologi, Institut Teknologi Sepuluh \\ Nopember (ITS)
}

\begin{abstract}
Abstrak - Ragam pengukuran kinerja dalam bisnis salah satunya dapat dibedakan berdasarkan finansial-non finansial. Dahulu aspek finansial menjadi satu-satunya yang diperhatikan dalam pengukuran kinerjanya, namun seiring berjalannya waktu, aspek non finansial ditemukan dan mulai digunakan dalam pengukuran kinerja bisnis. Sampai saat ini, kedua aspek tersebut saling melengkapi kebutuhan perusahaan dalam menilai kinerja elemen di dalamnya. Penelitian ini bertujuan untuk mengetahui ragam pengukuran kinerja pada UMKM di Surabaya. Penelitian dilakukan kepada pemilik UMKM di Surabaya dengan metode survei. Jenis data yang digunakan dalam riset adalah data primer yang bersumber dari responden penelitian. Data dianalisis secara deskriptif. Hasilnya, pengukuran kinerja pada UMKM di Surabaya terbagi menjadi aspek finansial dan non finansial secara merata.
\end{abstract}

Kata Kunci-Ragam Pengukuran Kinerja.

\section{PENDAHULUAN}

$\mathrm{P}$ ADA awalnya, pengukuran kinerja hanya didasarkan pada aspek finansial, namun seiring berjalannya waktu, pengusaha menyadari bahwa aspek non finansial merupakan bagian yang tidak terlepaskan dalam pencapaian suatu kinerja, dan untuk itu perlu dilengkapi dengan pengukuran kinerja non finansial. Pengukuran kinerja finansial hanya menitikberatkan pada keuntungan yang dinilai terlalu tertinggal karena hanya mengukur sesuatu yang telah dilalui dan tidak dapat dijadikan satu-satunya acuan untuk mengukur kinerja usaha secara harfiah [1].

Sejumlah penelitian hanya menitikberatkan pada pengukuran kinerja perusahaan dengan skala besar, dengan mengenyampingkan pentingnya pengukuran kinerja pada usaha yang lebih kecil atau Usaha Mikro, Kecil, dan Menengah (UMKM).

Untuk UMKM atau yang dalam bahasa inggris lebih dikenal sebagai Small and Medium Enterprise (SME), pengukuran kinerja yang digunakan berbeda karena karakteristik usaha yang berbeda pula [2]. Selain itu, pengukuran kinerja UMKM tidak diturunkan dari strategi, dimana seharusnya pengukuran kinerja berdasarkan hal tersebut [3]. UMKM berbeda dengan perusahaan besar karena hal-hal berikut: keterbatasan sumber daya manusia dan keuangan, beroperasi pada pasar yang sempit, struktur yang sejajar dan fleksibel. Keterbatasan sumber daya pada UMKM membuat dimensi kualitas dan waktu pengerjaan menjadi penting agar tingkat bahan yang terbuang tetap rendah, selain itu karena bergerak pada pasar yang sempit maka kepuasan konsumen harus dipertahankan. Selain itu, jumlah karyawan dan struktur organisasi yang fleksibel memungkinkan seseorang untuk bertanggungjawab pada banyak ranah, maka kualitas dan motivasi karyawan juga harus diperhatikan. Masalah yang timbul bagi beberapa UMKM adalah pengukuran yang rumit. Maka diperlukan kajian lebih lanjut mengenai penerapan ragam pengukuran kinerja pada UMKM.

Mengingat di Indonesia sendiri saat ini sedang digencarkan usaha dengan skala mikro, kecil, dan menengah. Dikarenakan, Kementerian Koperasi dan Usaha Mikro, Kecil, dan Menengah mencatat kontribusi sektor UMKM kepada PDB yang meningkat dari 57,84\% menjadi 60,34\% [4]. Selain itu, banyaknya UMKM khususnya di Jawa Timur juga menjadi alasan dalam perkembangan UMKM di Jawa Timur. Pada tahun 2014, terdapat 260.762 UMKM di Surabaya dengan rincian usaha mikro sebanyak 6.533.694, kecil sebanyak 261.827 dan menengah sebanyak 30.41 [5].

Dengan berdasar penelitian mengenai ragam pengukuran kinerja pada UMKM di berbagai negara, serta pengukuran kinerja di UMKM yang masih dianggap rumit memerlukan pengujian kembali dengan studi kasus di Indonesia. Hal ini menjadi alasan untuk dilakukan penelitian yang mengkonfirmasi ragam pengukuran kinerja pada UMKM dengan adaptasi pada negara Indonesia khususnya kota Surabaya.

\section{TINJAUAN PUSTAKA}

\section{A. Ragam pengukuran kinerja}

Ragam pengukuran kinerja adalah bagaimana top management memberikan bobot pada penilaian kinerja yang bersifat finansial dan non finansial [5]. Pengelompokan pengukuran kinerja dapat dilakukan menjadi finansial dan non finansial, kuantitatif dan kualitatif, pengukuran internal dan eksternal, serta pemicu dan hasil

\section{METODOLOGI PENELITIAN}

\section{A. Jenis Data}

Data yang digunakan dalam penelitian ini adalah data primer yakni hasil penyebaran kuesioner yang dilakukan pada UMKM di Surabaya.

\section{B. Pengumpulan Data}

Penelitian dilakukan dengan menggunakan metode survei melalui kuesioner yang disebar secara offline. Namun, terdapat beberapa kuesioner dalam bentuk online karena keterbatasan responden ketika ditemui oleh peneliti. Peneliti mendatangi UMKM di berbagai tempat seperti pameran dan di rumah masing-masing serta memilih UMKM berdasarkan yang bersedia menjadi responden.

Untuk variabel ragam pengukuran kinerja, peneliti mengacu pada perspektif yang digunakan oleh [6] yakni keuntungan, 
posisi arus kas, dan budget vs actual untuk dimensi finansial, serta kualitas produk dan kepuasan konsumen untuk dimensi non finansial.

Peneliti menggunakan skala interval yakni 5 poin skala likert untuk menguji variabel. 5 poin skala likert digunakan sebagai berikut: angka 1 untuk sangat tidak setuju dan 5 sangat setuju. Populasi dari riset ini adalah seluruh owner UMKM di Surabaya. Peneliti mengambil sampel dari populasi tersebut dengan teknik pengambilan sampel non probability sampling. Metode yang dipilih adalah convenience sampling yakni peneliti memiliki kebebasan untuk memilih responden berdasarkan pertimbangan pribadi [7]. Sejumlah 81 kuesioner disebar dari bulan Maret hingga April 2017. Analisis pada penelitian ini terdiri dari analisis deskriptif.

\section{IV.ANALISIS DAN PEMBAHASAN}

\section{A. Uji Validitas dan reliabilitas}

Validitas melihat apakah sebuah alat ukur yang digunakan dapat benar-benar mengukur dan memberikan hasil ukur sesuai dengan seharusnya [8]. Uji validitas melihat keabsahan setiap item pertanyaan dalam kuisioner dengan menggunakan Confirmatory Factor Analysis (CFA). Data dikatakan valid ketika nilai loading factor-nya mencapai 0,5 [9].

Menurut tabel 1, seluruh item pertanyaan dalam kuisioner telah memenuhi syarat validitas yakni loading factor $>0,5$. Maka data dapat dianalisis lebih lanjut yakni uji reliabilitas. Sedangkan dalam uji reliabilitas didapatkan hasil cronbach alpha secara keseluruhan lebih dari 0,6.

Tabel 1.

Hasil Uji Validitas Dan Reliabilitas Variabel Ragam Pengukuran Kinerja

\begin{tabular}{llll}
\hline \hline & Pernyataan & Loading factor & $\begin{array}{l}\text { Cronbach } \\
\text { alpha }\end{array}$ \\
\hline Financial & $\mathrm{A} 1$ & 0,803 & 0,738 \\
& $\mathrm{~A} 2$ & 0,889 & \\
& $\mathrm{~A} 3$ & 0,742 & \\
\hline Non-financial & $\mathrm{A} 4$ & 0,895 & 0,748 \\
& $\mathrm{~A} 5$ & 0,895 & \\
\hline \hline
\end{tabular}

\section{B. Analisis Deskriptif}

Analisis deskriptif demografi dilakukan untuk mengetahui distribusi dari responden penelitian. Berikut adalah hasil analisis demografi responden pada Tabel 2.

Menurut jenis usaha, mayoritas UMKM menjalankan usaha pada bidang fashion. Sebanyak 27 dari 81 responden memilih bidang ini, diikuti oleh bidang kuliner sebanyak 26 responden, kerajinan sebanyak 15 responden, kafe sebanyak 4 responden, electronic project sebanyak 3 responden, retail dan digital printing 2 responden, dan masing-masing 1 UMKM untuk bidang body care serta jasa cuci sepatu. Terlihat bahwa bidang UMKM yang paling banyak diminati adalah fashion, diantaranya adalah batik, tenun, tas, sepatu, aksesoris, bordir dan jahit, serta baju muslim. Diikuti oleh bidang kuliner yang bervariasi mulai dari cemilan tradisional, cemilan modern, kue kering, puding, minuman herbal, kopi, dan minuman tradisional. Selanjutnya kerajinan diantaranya kotak tisu, hantaran, kotak kemasan berbahan dasar daun dan kertas semen, aksesori etnik, dan boneka.
Tabel 2.

Profil Responden

\begin{tabular}{|c|c|}
\hline Profil & Frekuensi \\
\hline \multicolumn{2}{|l|}{ Jenis kelamin } \\
\hline Laki-laki & 31 \\
\hline Perempuan & 50 \\
\hline Total & 81 \\
\hline \multicolumn{2}{|l|}{ Umur pemilik } \\
\hline$<25$ tahun & 8 \\
\hline 25-30 tahun & 11 \\
\hline 35-40 tahun & 18 \\
\hline$>40$ tahun & 27 \\
\hline Total & 81 \\
\hline \multicolumn{2}{|l|}{ Jenis usaha } \\
\hline Industri pengolahan & 69 \\
\hline Perdagangan, hotel & 6 \\
\hline Jasa & 6 \\
\hline Total & 81 \\
\hline \multicolumn{2}{|c|}{ Penggunaan pengukuran kinerja non finansial } \\
\hline Ya & 81 \\
\hline Tidak & 0 \\
\hline Total & 81 \\
\hline \multicolumn{2}{|l|}{ Lama usaha } \\
\hline$\leq 1$ tahun & 57 \\
\hline $2-5$ tahun & 38 \\
\hline $6-10$ tahun & 5 \\
\hline$>10$ tahun & 10 \\
\hline Total & 81 \\
\hline \multicolumn{2}{|l|}{ Jumlah karyawan } \\
\hline$\leq 10$ orang & 65 \\
\hline $11-30$ orang & 11 \\
\hline $31-300$ orang & 4 \\
\hline$>300$ orang & 1 \\
\hline Total & 81 \\
\hline \multicolumn{2}{|l|}{ Omzet } \\
\hline$\leq 300$ juta rupiah & 67 \\
\hline$>300$ juta $-2,5$ miliar rupiah & 12 \\
\hline$>2,5$ miliar -50 miliar rupiah & 2 \\
\hline Total & 81 \\
\hline \multicolumn{2}{|l|}{ Frekuensi penilaian kinerja } \\
\hline 1 kali & 25 \\
\hline 2 kali & 19 \\
\hline 3 kali & 13 \\
\hline lebih dari 3 kali & 24 \\
\hline Total & 81 \\
\hline \multicolumn{2}{|l|}{ Lama penerapan penilaian kinerja } \\
\hline$\leq 1$ tahun & 38 \\
\hline $2-5$ tahun & 34 \\
\hline$>5$ tahun & 9 \\
\hline Total & 81 \\
\hline
\end{tabular}

Jika mengacu pada klasifikasi sektor ekonomi, maka industri pengolahan menjadi yang tertinggi (69 responden), dengan didalamnya terdapat usaha kuliner, kerajinan, body care, dan fashion. Disusul oleh perdagangan, hotel, dan restoran yang didalamnya terdapat kafe dan retail serta sektor jasa (digital printing, cuci sepatu dan electronic project).

Seluruh responden menyatakan menggunakan pengukuran kinerja non finansial sebagai pelengkap dari pengukuran kinerja finansial. Pengukuran kinerja non finansial yang dimaksud antara lain kualitas produk dan kepuasan pelanggan. Selanjutnya, mayoritas UMKM yang diteliti merupakan usaha yang telah berjalan selama 2-5 tahun yakni sebanyak 45 dari 81 UMKM, diikuti oleh usaha yang telah berjalan selama 6-10 tahun, lebih dari 10 tahun, dan kurang dari 1 tahun. Hal ini 
menunjukkan bahwa UMKM telah banyak yang berusia cukup matang untuk mengembangkan bisnisnya.

UMKM yang diteliti mayoritas masih memiliki karyawan dengan jumlah yang sedikit. Hal ini dapat dikaitkan dengan klasifikasi UMKM menurut Bank Dunia yakni usaha mikro dengan karyawan maksimal 10 orang, usaha kecil dengan karyawan maksimal 30 orang, dan usaha menengah jika memiliki jumlah karyawan 300 orang [10]. Dapat disimpulkan bahwa usaha yang diteliti mayoritas merupakan usaha mikro.

Jika dilihat dari omzet, usaha yang diteliti dapat digolongkan menjadi usaha mikro dengan omzet maksimal 300 juta rupiah, usaha kecil dengan omzet maksimal 2,5 miliar rupiah, dan usaha menengah dengan omzet maksimal 50 miliar [10]. Sama seperti grafik sebelumnya yang menunjukkan mayoritas responden berasal dari usaha skala mikro. Meski tidak menutup adanya usaha skala kecil dan menengah, namun hal ini dapat menjadi pertimbangan bahwa mayoritas usaha yang banyak digeluti masyarakat adalah usaha mikro.

Responden yang seluruhnya merupakan pemilik dari UMKM terbagi menjadi responden dengan umur diatas 40 tahun sebagai responden mayortas, diikuti oleh umur 35-40 tahun, dibawah 25 tahun, 31-35 tahun, dan 25-30 tahun. Dapat disimpulkan bahwa mayoritas pemilik UMKM adalah mereka yang berada pada usia lanjut, yang merintis usaha sejak lama dan membutuhkan pendampingan yang berbeda-beda sesuai usianya. Hal ini telah diakomodasi oleh pemerintah dengan mengadakan pelatihan bisnis sesuai bidang usaha dan usia pemilik.

Dari jenis kelamin, terlihat bahwa mayoritas pemilik UMKM adalah perempuan. Dapat menjadi pertimbangan pula untuk merancang pelatihan yang disesuaikan oleh karakteristik pemilik UMKM di Surabaya ini.

Sebagai UMKM, umumnya penilaian kinerja dilakukan secara tidak sistematis. Namun hal berbeda nampak pada hasil penelitian yang menunjukkan UMKM menilai kinerja setiap tahunnya sebanyak satu kali, bahkan terdapat UMKM yang melakukan pengukuran kinerja lebih dari $3 \mathrm{x}$ dalam satu tahun. Biasanya penilaian kinerja dilakukan setiap 3 bulan sekali atau bahkan satu bulan sekali.

Penilaian kinerja telah dilakukan di UMKM selama 1 tahun belakangan. Ada pula yang telah mengaplikasikan penilaian kinerja dalam kurun waktu 2-5 tahun sampai lebih dari 5 tahun sejak bisnis didirikan. Hal ini menyiratkan bahwa kesadaran UMKM akan penilaian kinerja masih sangat kurang, meski pada grafik sebelumnya dijelaskan bahwa banyak pula UMKM yang melakukan penilaian kinerja setiap bulan, namun hal ini baru dilakukan pada setahun terakhir. Selanjutnya analisis deskriptif untuk dimensi finansial dapat dilihat pada Tabel 3.

UMKM mengukur kinerja finansial melalui ketiga hal berikut ini : keuntungan, posisi arus kas, dan budget vs actual. Mengukur kinerja finansial menjadi sesuatu yang mutlak terjadi, dalam perusahaan maupun UMKM. Sementara itu tidak ditemukan jawaban responden yang menyimpang jauh, hal ini ditunjukkan dengan standar deviasi yang tidak lebih dari 1. Analisis statistik dimensi non finansial dapat dilihat pada Tabel 4.
Tabel 3

Analisis Deskriptif Dimensi Finansial

\begin{tabular}{cccccccc}
\hline \hline Pernyataan & STS & TS & CS & S & SS & $\begin{array}{c}\text { Rata- } \\
\text { rata }\end{array}$ & $\begin{array}{c}\text { Standar } \\
\text { deviasi }\end{array}$ \\
\hline A27 & 1 & 5 & 14 & 52 & 9 & 3,78 & 0,77 \\
A28 & 1 & 6 & 16 & 46 & 12 & 3,77 & 0,84 \\
A29 & 2 & 6 & 18 & 44 & 11 & 3,69 & 0,89 \\
\hline \hline
\end{tabular}

Tabel 4.

Analisis Deskriptif Dimensi Non Finansial

\begin{tabular}{cccccccc}
\hline \hline Pernyataan & STS & TS & CS & S & SS & $\begin{array}{c}\text { Rata- } \\
\text { rata }\end{array}$ & $\begin{array}{c}\text { Standar } \\
\text { deviasi }\end{array}$ \\
\hline A30 & 1 & 6 & 16 & 46 & 12 & 3,77 & 0,84 \\
A31 & 2 & 6 & 18 & 44 & 11 & 3,69 & 0,89 \\
\hline \hline
\end{tabular}

UMKM juga mengukur kinerja melalui aspek non finansial. Meski tidak menjadi acuan utama, dan beberapa UMKM memandang keberhasilan tidak dapat diukur dari aspek non finansial, namun mayoritas UMKM melihat aspek non finansial sebagai sesuatu yang penting karena untuk bertahan dalam bisnis terkadang bukan keuntungan yang dicari namun kepercayaan pelanggan. UMKM hanya mengandalkan rekomendasi dan mouth to mouth untuk mempromosikan bisnisnya. Maka pelanggan adalah yang terpenting. Selain itu tidak ditemukan jawaban responden yang menyimpang jauh, hal ini ditunjukkan dengan standar deviasi yang tidak lebih dari 1.

Secara umum, UMKM sama-sama meletakkan aspek finansial dan non finansial secara seimbang, meski penerapan pengukuran kinerja biasanya tidak dilakukan secara formal.

Menurut hasil turun lapang didapatkan bahwa penggunaan aspek pengukuran kinerja pada UMKM telah dilakukan, namun pada kenyataannya dilakukan secara informal. Padahal jika dikaitkan dengan data kontribusi UMKM terhadap PDB Indonesia yang telah diulas sebelumya, hal ini tentu sangat memprihatinkan. UMKM seharusnya mampu untuk lebih didorong produktivitasnya dan memahami pentingnya pengukuran kinerja dalam menilai pencapaian bisnis dan melakukan perbaikan pada aspek yang diperlukan.

Selama ini UMKM hanya menilai bisnis tanpa melihat elemen yang berada di dalamnya. Maka, UMKM hendaknya menerapkan sistem pengukuran kinerja untuk karyawan. Aspek kedisiplinan karyawan dapat dinilai pula sebagai sandingan dari pengukuran kinerja bisnis karena profesionalitas dalam pekerjaan juga semakin dituntut meski UMKM berjalan dengan dasar kekeluargaan. Meski terkesan disamaratakan, namun hendaknya pihak pemilik UMKM memperhatikan potensi masing-masing karyawan yang memungkinkan untuk menempati posisi yang lebih tinggi di masa yang akan datang.

Hal ini tentu dapat menjadi masukan bagi Dinas Koperasi dan UMKM kota Surabaya atau provinsi Jawa Timur untuk mengadakan pelatihan mengenai penilaian kinerja pada UMKM ke depannya agar UMKM lebih memahami bagaimana mengukur kinerja secara sistematis dan tepat guna sehingga kinerja UMKM juga meningkat. Karena menurut hasil turun lapang didapatkan bahwa saat ini pelatihan yang telah diberikan kepada UMKM di Surabaya hanya pelatihan seputar penggalian ide pemasaran, packaging, keuangan sederhana, serta ditingkatkannya partisipasi UMKM dalam pameran yang diadakan oleh berbagai pihak. 


\section{KESIMPULAN}

Secara umum, UMKM sama-sama meletakkan aspek finansial dan non finansial secara seimbang, meski penerapan pengukuran kinerja biasanya tidak dilakukan secara formal. UMKM di Surabaya mayoritas bergerak pada industri pengolahan (69 responden), dengan didalamnya terdapat usaha kuliner, kerajinan, body care, dan fashion. Disusul oleh perdagangan, hotel, dan restoran yang didalamnya terdapat kafe dan retail serta sektor jasa (digital printing, cuci sepatu dan electronic project).

Seluruh responden menyatakan menggunakan pengukuran kinerja non finansial sebagai pelengkap dari pengukuran kinerja finansial. Pengukuran kinerja non finansial yang dimaksud antara lain kualitas produk dan kepuasan pelanggan.

\section{UCAPAN TERIMA KASIH}

Penulis mengucapkan terima kasih kepada Dinas Koperasi dan UMKM Kota Surabaya, kedua orang tua dan teman-teman Manajemen Bisnis ITS 2013 memberi dukungan hingga penelitian ini dapat diselesaikan.

\section{DAFTAR PUSTAKA}

[1] J. F. Henri, "Organizational culture and performance measurement systems," Accounting, Organ. Soc., pp. 77-103, 2006.

[2] D. Storey, Understanding the Small Business Sector. London: International Thompson Business Press., 1994.

[3] M. Hudson and A. Smart, "Theory and practice in SME performance measurement system," Int. J. Oper. Prod. Manag., pp. 2096-2225, 2001.

[4] Dinas Koperasi dan UMKM Jawa Timur, "Data UMKM," 2016. [Online]. Available: http://diskopumkm.jatimprov.go.id/viewmedia.php?pages $=$ content $\&$ id $=57 \&$ bidang $=$.

[5] C. D. Ittner, "Subjectivity and the weighting of performance measures:evidence from a balanced scorecard," Account. Rev., vol. 78, no. 3, pp. 725-728, 2003.

[6] M. Harif, C. Hoe, and M. Ahmad, "The Financial and Non-Financial Performance Indicators of Paddy Farmers Organization," World Rev. Bus. Res., pp. 80-102, 2013.

[7] D. R. Cooper and P. S. Schindler, Business Research Method. Singapore: Mc Graw Hill, 2011.

[8] S. Azwar, Reliabilitas dan Validilitas: Interpretasi dan Komputasi. Yogyakarta: Liberty, 1986.

[9] Hair and J. H, Multivariate data analysis. New York: Prentice Hall, 2010.

[10]BI, "Profil Bisnis UMKM," 2015. [Online]. Available: http://www.bi.go.id/id/umkm/penelitian/ nasional/ kajian/ Documents/Profil Bisnis UMKM.pdf. 